\title{
Colonizing Mars
}

No human being has set foot on an astronomical body other than Earth since 1972. One can argue that there's no pressing need to do so, going back to the Moon - or further, to Mars or some other planet especially with actual people. Unmanned spacecraft can do an awful lot of useful science. It would be a waste of resources to send people, and we have enough other pressing problems. Right? NASA does have plans for Mars, but envisions human astronauts going there only sometime in the 2030s.

However, there is another perspective. Catastrophic events on Earth have previously wiped out many long-lived species, and there's a small but non-zero chance that Earth could, in any given year, get obliterated - by an undetected asteroid or comet, or a nearby supernovae. Or human life might get erased from the planet by our inaction in the face of the pressures we're putting on the biosphere, or by overaction in the form of an out-of-control engineered biological organism. Given enough time, human extinction might be a more or less certain prospect - unless we spread from the planet. From this perspective, efforts to spread our species to other astronomical objects seems rather more urgent.

It's this argument that lies behind the efforts of Elon Musk, who recently announced plans for his company SpaceX to work toward taking paying passengers to Mars by 2022 . His vision is hugely ambitious, inspiring, and also admirably practical. It's motivated by the perception that human technical capabilities don't advance automatically, but only if we decide to focus our scientific, engineering and industrial effort on a specific goal. That said, the project does face some imposing and unsolved hurdles

Why Mars? First, it's not too far away, and far more hospitable than alternatives such as Venus or Mercury. The Martian day is 24 hours and 40 minutes, and temperatures range from $-140{ }^{\circ} \mathrm{C}$ to $30^{\circ} \mathrm{C}$, compared to Earth's slightly warmer $-88^{\circ} \mathrm{C}$ to $58^{\circ} \mathrm{C}$. If we could warm Mars a little, it could be much like Earth, with a dense gaseous atmosphere and liquid oceans. Plentiful $\mathrm{CO}_{2}$ in the atmosphere also means we could grow plants. There's decent sunlight given that Mars is only $50 \%$ further from the Sun than Earth.

Musk's path to getting lots of people to Mars - and making humanity a multiplanet

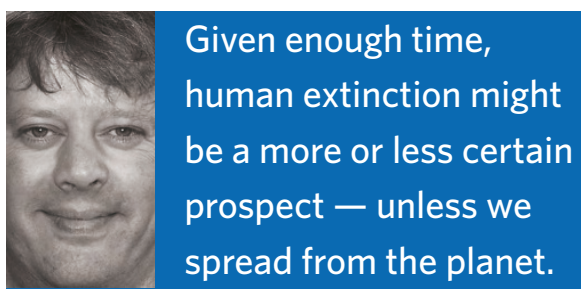

Mars itself, so that ships sent to Mars could return to Earth. This should be possible, he suggests, given that the Martian atmosphere is predominantly $\mathrm{CO}_{2}$, with water and ice present in the soil. Both methane $\left(\mathrm{CH}_{4}\right)$ and oxygen $\left(\mathrm{O}_{2}\right)$ can then be produced as a fuel source. In Musk's vision, this would fuel a fleet of spaceships that would in time come to number as many as 1,000. Each ship would carry about 100 people on a trip of 80 days, and would, of course, need to carry an incredibly wide range of cargo to support everything from manufacturing and oxygen production to farming and entertainment. Building up a sustainable population on Mars - of, say, one million people would take many decades, possibly as long as a century.

Musk goes on to examine the kind of engine technology that might be used, based on the recent technological success of his company SpaceX. This part of the story seems quite believable, especially given the impressive progress SpaceX has had over the past decade or so. It's become the largest private producer of rocket engines in the world, and produces the engine giving the highest ever thrust to weight ratio. It's also mastered technology to have rocket boosters return to their launch sites and land carefully back on the pad.

One big stumbling block — one Musk doesn't mention in his essay - is radiation. Earth has a nice magnetosphere that largely protects us from the harsh solar wind and high-energy cosmic rays arriving from outer space. Travelling through space to Mars presents serious risks to astronauts; this remains the primary risk as viewed by analysts at NASA. There appear to be few technical solutions to shield astronauts, who may inevitably suffer serious radiation damage.

Yes, of course - going to Mars en masse is risky, the method unproven and uncertain, still awaiting invention. But historically, this is often how amazing scientific, technological or cultural accomplishments have come about. On occasion, as our capabilities advance, something that for so long seemed impossible suddenly becomes possible, given the right sustained effort. Musk's vision aims for just such a change. It may all end in disappointment and failure. But, even then, we're sure to learn many things along the way.

MARK BUCHANAN 